\title{
Methylation profile of hepatitis B virus is not influenced by interferon $\alpha$ in human liver cancer cells
}

\author{
IN YOUNG MOON ${ }^{1}$ and JIN-WOOK KIM ${ }^{1,2}$ \\ ${ }^{1}$ Department of Medicine, Seoul National University Bundang Hospital, Seongnam, Gyeonggi 13620; \\ ${ }^{2}$ Department of Internal Medicine, Seoul National University College of Medicine, Seoul 03080, Republic of Korea
}

Received December 20, 2020; Accepted July 12, 2021

DOI: $10.3892 / \mathrm{mmr} .2021 .12354$

\begin{abstract}
Interferon (IFN) $\alpha$ is used for the treatment of chronic hepatitis B virus (HBV) infection, but the molecular mechanisms underlying its antiviral effect have not been fully elucidated. Epigenetic modifications regulate the transcriptional activity of covalently closed circular DNA (cccDNA) in cells with chronic HBV infection. IFN- $\alpha$ has been shown to modify cccDNA-bound histones, but it is not known whether the anti-HBV effect of IFN- $\alpha$ involves methylation of cccDNA. The present study aimed to determine whether IFN- $\alpha$ induced methylation of HBV cccDNA in a cell-based model in which HepG2 cells were directly infected with wild-type HBV virions. Methylation status of HBV cccDNA was assessed using global DNA methylation ELISA assay, methylation-specific PCR and bisulfite sequencing. IFN- $\alpha$ suppressed HBV DNA and RNA transcripts, but methylation profiles were similar between the control and IFN- $\alpha$ treated groups. Chromatin immunoprecipitation results revealed binding of DNA methyltransferases (DNMT) 3A and DNMT3B to HBV cccDNA and treatment with IFN- $\alpha$ suppressed the recruitment of DNMT3B to cccDNA. Taken together, these results suggest that IFN- $\alpha$ does not induce methylation of HBV cccDNA. Therefore, it was concluded that methylation is unlikely to contribute to the anti-HBV effect of IFN- $\alpha$ in HepG2 cells, and that alternative mechanisms need to be sought to enhance cccDNA methylation as a novel therapy against HBV.
\end{abstract}

Correspondence to: Professor Jin-Wook Kim, Department of Medicine, Seoul National University Bundang Hospital, 82 Gumi-ro 173 Beon-gil, Bundang, Seongnam, Gyeonggi 13620, Republic of Korea

E-mail:kimjw@snubh.org

Abbreviations: HBV, hepatitis B virus; rcDNA, relaxed circular DNA; cccDNA, covalently closed circular DNA; DNMT, DNA methyltransferase; IFN, interferon

Key words: epigenetic modification, hepatitis B virus, interferon $\alpha$, methylation

\section{Introduction}

Hepatitis B virus (HBV) is one of the commonest causes of chronic hepatitis worldwide (1). The chronicity of HBV infection is related to the fact that HBV produces very stable viral genome in the host cells (1). The HBV genome is partially double-stranded relaxed circular DNA (rcDNA), which is converted to complete double-stranded covalently closed circular DNA (cccDNA) in the nucleus of infected hepatocytes (2). HBV cccDNA remains the main hurdle in the eradication of infected HBV as current antiviral agents cannot eradicate this episomal viral minichromosome (3). HBV cccDNA persists in the liver throughout the natural course of chronic HBV infection.

Serum HBV DNA, a standard surrogate marker of HBV replication in hepatocytes, decreases over time during the natural course of infection in numerous patients with chronic hepatitis B (CHB) (4). In addition, some of them lose serum HBsAg which is a sensitive marker of HBV infection and controlled by a separate promoter (2). These findings suggest that the transcriptional activity of HBV cccDNA may decrease in the late stage of infection. Indeed, recent studies confirm transcriptional suppression of cccDNA in HBeAg-negative chronic hepatitis $\mathrm{B}(5,6)$. The transcriptional activity of $\mathrm{HBV}$ cccDNA is controlled by four promoters (precore/pregenomic, S1, S2 and X) and two enhancer sequences (enhancer I and enhancer II) (7). These cis-regulatory elements recruit several ubiquitous and liver-specific transcription factors and contribute to the regulation of cccDNA transcription $(8,9)$.

In addition to the trans-acting DNA-binding proteins, structural changes in cccDNA, i.e., epigenetic modifications, have been implicated as regulatory mechanisms of cccDNA transcription $(10,11)$. Electron microscopy examination of cccDNA reveals typical 'beads-on-a-string' nucleosomal organization (12). HBV nucleoprotein is composed of HBV core protein and histones (13). Similar to the case of mammalian cellular DNA, posttranslational modifications (PTMs) of histone proteins modulate the transcription of $\mathrm{HBV}$ cccDNA (8). Acetylation of cccDNA-bound $\mathrm{H} 3 / \mathrm{H} 4$ histones was first reported to promote HBV replication (14). Thereafter, a genome-wise map of PTMs revealed that stimulatory PTMs, such as H3K4me3, H3K27ac and H3K122ac are enriched, whereas suppressive PTMs, including H3K9me3 and H3K27me3, are underrepresented in cccDNA chromatin (15). 
Recently, succinylation of H3K79 was reported to upregulate cccDNA transcription (16). Thus, PTMs of histone proteins are now considered to be major regulators of cccDNA transcription.

Methylation of HBV cccDNA has also been pursued as a regulatory mechanism for cccDNA transcription (17-20). There are two CpG island sequences (II and III) which are conserved across the eight major genotypes (21) and are hotspots for methylation of cccDNA isolated from human liver tissues (22). In particular, $\mathrm{CpG}$ II is located near the core promoter and methylation densities on $\mathrm{CpG}$ II are correlated with $\mathrm{HBeAg}$ status (17), transcriptional activity of cccDNA (20) and serum HBV DNA levels $(20,22)$. De novo methylation of mammalian DNA is mediated by DNA methyltransferases (DNMT) 3A and DNMT3B, but the mechanisms underlying the methylation process of cccDNA are poorly understood (23).

Interferon (IFN) $\alpha$ has long been used as an antiviral therapy for CHB. The antiviral effect of IFN- $\alpha$ is modest and observed in only a portion of patients compared to that of nucleos(t)ide analogues (1). However, patients responding to interferon treatment typically show durable viral suppression after cessation of therapy (24), suggesting induction of persistent antiviral milieu in hepatocytes. Diverse interferon-stimulated genes (ISGs) work at the transcriptional and post-transcriptional levels to keep HBV replication in check (25-28), but the downstream intracellular mechanisms responsible for the durable interferon response remain to be elucidated. Previous studies have shown that IFN- $\alpha$ induces modification of cccDNA-bound histones $(15,16,29,30)$. These epigenetic modifications may explain the transcriptional suppression of cccDNA and off-treatment sustained HBV suppression by IFN- $\alpha$ (31). However, while IFN- $\alpha$ treatment reduces the stimulatory PTMs (H3K4me3, H3K9ac H3K27ac and H3K122ac), H3K9me3 and H3K27me3, the canonical repressive PTMs, are not enriched by IFN- $\alpha$, suggesting that additional active epigenetic mechanisms may contribute to selective silencing of the precore/pregenomic HBV promoter by IFN- $\alpha(15,28)$. Considering the suppressive role of $\mathrm{CpG}$ II methylation during the natural course of $\mathrm{HBV}$ infection, it is hypothesized that IFN- $\alpha$ treatment may induce changes in the methylation status of cccDNA, a hypothesis not yet tested. Thus, the aim of the present study was to elucidate the effect of IFN- $\alpha$ on the methylation status of HBV cccDNA in a cell-based HBV replication system.

\section{Materials and methods}

In vitro $H B V$ replication model. Infectious $H B V$ particles were collected from HepAD38 cells (a gift from Professor C. Seeger, Fox Chase Cancer Center, PA), which allow HBV replication under the control of an inducible tetracycline promoter (32). The cells were cultured in Dulbecco's modified Eagle's medium (DMEM)/F12 medium (Welgene, Inc.) containing $10 \%$ fetal bovine serum, $100 \mathrm{U} / \mathrm{ml}$ penicillin, $100 \mu \mathrm{g} / \mathrm{ml}$ streptomycin, $0.3 \mu \mathrm{g} / \mathrm{ml}$ tetracycline and $400 \mu \mathrm{g} / \mathrm{ml}$ $\mathrm{G} 418$ at $37^{\circ} \mathrm{C}$ in a $5 \%$ carbon dioxide chamber. HBV replication was induced by omitting tetracycline from the culture medium for 5-7 days. The culture supernatant was centrifuged at $12,000 \mathrm{xg}$ for $5 \mathrm{~min}$ at room temperature to remove cellular debris and then ultracentrifuged at $25,000 \mathrm{xg}$ for $4 \mathrm{~h}$ at $4^{\circ} \mathrm{C}$.
The pellets were resuspended in PBS and the viral titer was measured using reverse transcription-quantitative (RT-q) PCR. HepG2 cells, a human liver cancer cell line (cat. no. 88065, passage number 5-10, Korean Cell Line Bank, Seoul, South Korea), were infected with HBV particles at a titer of 50 multiplicity of infection (MOI) in the presence of DMSO (cat. no. H 9268; final concentration of $0.2 \%$; Sigma-Aldrich; Merck KGaA) because DMSO facilitates intracellular entry of HBV and enhances intracellular replication $(33,34)$. The cells were then maintained in DMEM containing 10\% fetal bovine serum, penicillin and streptomycin. On the following day, IFN- $\alpha$ (Intron A; MSD International GmbH; $15 \mathrm{MU} / \mathrm{ml}$ ) was replenished at a final concentration of $1,500 \mathrm{U} / \mathrm{ml}$ for four days before harvest.

Isolation of HBV rcDNA and $c c c D N A$. HBV-infected HepG2 cells that were grown in a $60-\mathrm{mm}$ tissue culture dish at a density of $5 \times 10^{5}$ cells $/ \mathrm{ml}$ were lysed with $0.4 \mathrm{ml}$ of cell lysis buffer [50 mM Tris-HCl, pH 8.0; 1 mM EDTA, 0.2\% (v/v) Nonidet P-40 and $0.15 \mathrm{M} \mathrm{NaCl}]$. The lysate was centrifuged at $16,000 \mathrm{x} \mathrm{g}$ at $4^{\circ} \mathrm{C}$ for $2 \mathrm{~min}$ and the nuclear pellet was used for cccDNA extraction (as follows) and the supernatant was used to isolate core particle-associated HBV rcDNA (35). Briefly, the cytoplasmic fraction was treated with $1 / 4$ volume of 35\% PEG8000 in $1.75 \mathrm{M} \mathrm{NaCl}$, incubated on ice for $30 \mathrm{~min}$ and centrifuged at $16,000 \mathrm{x}$ g for $10 \mathrm{~min}$. The precipitated viral particles were dissolved in DNA extraction buffer $(10 \mathrm{mM}$ Tris- $\mathrm{HCl}, \mathrm{pH} 8.0 ; 100 \mathrm{mM} \mathrm{NaCl} ; 1 \mathrm{mM}$ EDTA; 0.5\% SDS; $200 \mu \mathrm{g} / \mathrm{ml}$ proteinase $\mathrm{K}$ ) at $45^{\circ} \mathrm{C}$ for $1 \mathrm{~h}$ and viral DNA was recovered by phenol-extraction and ethanol-precipitation (36). HBV cccDNA was extracted by dissolving the nuclear pellet in the DNA extraction buffer, followed by phenol-extraction and ethanol-precipitation. Contaminating genomic DNA was removed using treatment with Plasmid-Safe DNase (Epicentre; Illumina, Inc.).

Quantification of HBV using RT-qPCR, Southern blotting and northern blotting. SYBR Green RT-qPCR was performed to quantify HBV rcDNA and cccDNA. Primers for HBV rcDNA were GAGTGTGGATTCGCACTCC (forward) and GAG GCGAGGGAGTTCTTCT (reverse) (37) and for cccDNA were GCGGCTCCCCGTCTGTGCC, GTCTGTGCCTTC TCATCTGC (forward) and GTCCATGCCCCAAAGCAACC (reverse) (38) at a final concentration of $200 \mathrm{nM}$. The Thermal Cycler Dice Real Time System (Takara Bio, Inc.) was used according to the manufacturer's instructions. The PCR cycling program for $\mathrm{HBV}$ rcDNA consisted of an initial denaturing step at $95^{\circ} \mathrm{C}$ for $15 \mathrm{~min}$, followed by 45 amplification cycles at $95^{\circ} \mathrm{C}$ for $10 \mathrm{sec}, 60^{\circ} \mathrm{C}$ for $20 \mathrm{sec}$ and $72^{\circ} \mathrm{C}$ for $30 \mathrm{sec}$. The cycles for HBV cccDNA were initial denaturation at $95^{\circ} \mathrm{C}$ for $15 \mathrm{~min}$, followed by 45 amplification cycles at $95^{\circ} \mathrm{C}$ for $15 \mathrm{sec}, 63^{\circ} \mathrm{C}$ for $10 \mathrm{sec}$ and $72^{\circ} \mathrm{C}$ for $25 \mathrm{sec}$. The mitochondrial DNA gene was used for normalization: GCCTGCCTGATC CTCCAAAT (forward) and AAGGTAGCGGATGATTCA GCC (reverse). The Thermal Cycler Dice Real Time System (ver. 6.0.1A, Takara Bio, Inc.) was used for analysis according to the manufacturer's instructions.

Southern and northern blots for HBV rcDNA and RNA were performed using a digoxigenin-labeled RNA probe as previously reported $(39,40)$. Briefly, $15 \mu \mathrm{g}$ of HBV rcDNA 
was electrophoresed on a $1 \%$ agarose/Tris-Borate EDTA gel, which was depurinated with $\mathrm{HCl}(0.25 \mathrm{M})$ for $15 \mathrm{~min}$ and denatured in $\mathrm{NaOH}(0.5 \mathrm{M})$ for $15 \mathrm{~min}$. DNA was transferred to a Hybond-N+ membrane (Roche Diagnostics $\mathrm{GmbH}$ ) by capillary transfer. The membrane was UV cross-linked and hybridized with digoxygenin-tagged HBV RNA probes in Dig Easy Hybridization Buffer (Roche Diagnostics GmbH; $20 \mathrm{ng} / \mathrm{ml}$ stock diluted to $1: 5,000)$ overnight at $60^{\circ} \mathrm{C}$. The membrane was washed twice for $5 \mathrm{~min}$ at room temperature in $2 \mathrm{X} \mathrm{SSC}, 0.1 \% \mathrm{SDS}$ and for $15 \mathrm{~min}$ at $60^{\circ} \mathrm{C}$ in $0.1 \mathrm{X} \mathrm{SSC}, 0.1 \%$ SDS. The membrane was blocked with blocking reagent (Roche Diagnostics $\mathrm{GmbH}$ ) for $30 \mathrm{~min}$ at room temperature and incubated for $30 \mathrm{~min}$ in blocking buffer containing $187.5 \mathrm{mU} / \mathrm{ml}$ (1:4,000 v:v) anti-digoxygenin-alkaline phosphate antibody (Roche Diagnostics GmbH) followed by Immun-Star AP Substrate (Bio-Rad Laboratories, Inc.) treatment, and exposed to X-ray film.

For northern blotting, the cytoplasmic fraction was isolated as described above and treated with TRIzol ${ }^{\circledR}$ (Thermo Fisher Scientific, Inc.) and $5 \mu \mathrm{g}$ of RNA was separated on $1 \%$ agarose gel. Equal loading was examined by staining the gels with ethidium bromide and the RNA was transferred onto nylon membranes. Transferred RNA was detected in the same way as Southern blotting analysis.

Analysis of methylation profiles of $H B V$. The 5-mC dot blot assay was performed to assess the global methylation of HBV cccDNA using mouse anti-5-methylcytosine antibody (cat. no. 33D3; Active Motif, Inc.) as previously reported (41). Briefly, 50 ng of HBV cccDNA was blotted onto a Hybond-N+ membrane, UV-cross linked and subjected to immunodetection with 1:5,000 diluted anti-5mC antibody.

Global methylation of cccDNA was quantified by MethylFlash Global DNA Methylation (5-mC) ELISA Easy kit (cat. no. P-1030; EpiGentek Group Inc.) according to the manufacturer's protocols. A total of $100 \mathrm{ng}$ of cccDNA was used for the assay.

Bisulfite modification of HBV cccDNA was performed as previously reported (42). Methyl Primer Express (v1.0; Applied Biosystems; Thermo Fisher Scientific, Inc.) was used to design primers for methylation-specific PCR for CpG island II, which is relevant for transcriptional control of HBV replication as described previously $(21,43)$ : For unmethylated DNA, GTG GGATGTTTTTTGTTTAT (forward) and AACAAAAAA TCCACATAAAA (reverse; for methylated DNA, GCGGGA CGTTTTTTGTTTAC (forward) and AACGAAAAATCC GCGTAAAA (reverse) were used. The PCR mixture contained TOPreal qPCR 2X PreMIX (Enzynomics Co., Ltd.), primers $(200 \mathrm{nM})$ and $50 \mathrm{ng}$ of bisulfite-modified DNA in a final volume of $50 \mu \mathrm{l}$. PCR cycles were as follows: Initial activation at $95^{\circ} \mathrm{C}$ for $5 \mathrm{~min}$, followed by 35 cycles of $94^{\circ} \mathrm{C}$ for $30 \mathrm{sec}, 55^{\circ} \mathrm{C}$ for $30 \mathrm{sec}, 72^{\circ} \mathrm{C}$ for $30 \mathrm{sec}$ and a final $5 \mathrm{~min}$ extension at $72^{\circ} \mathrm{C}$. The PCR amplicons were quantified via densitometric analysis of $1 \%$ ethidium bromide-stained agarose gels. PCR was performed to measure the relative amount of methylation using the same primer pairs for methylation and normalized using the unmethylated primer pair. Bisulfite sequencing was performed to detect the methylation of $\mathrm{CpG}$ island II (39). The cloned sequences were analyzed using a BiQ Analyzer (Max Planck Institut Informatik; https://biq-analyzer.bioinf.mpi-inf.mpg.de/) (44).
Chromatin immunoprecipitation (ChIP) assay, western blotting and luciferase assay for DNA methyltransferases. ChIP assay was performed as previously reported (45), with minor modifications. Briefly, formaldehyde (cat. no. F8775; Sigma-Aldrich; Merck KGaA) was added directly to trypsinized HepG2 cells in PBS at a final concentration of $1 \%$ at room temperature for $10 \mathrm{~min}$ for fixation. The process was stopped with the addition of $0.125 \mathrm{M}$ final concentration of glycine. HepG2 cells were collected using centrifugation at $300 \mathrm{x} \mathrm{g}$ for $3 \mathrm{~min}$ at $4^{\circ} \mathrm{C}$ and rinsed with cold phosphate-buffered saline. The cell pellets were resuspended in MC lysis buffer [10 mM Tris-Cl, pH 7.5; $10 \mathrm{mM} \mathrm{NaCl;} 3 \mathrm{mM} \mathrm{MgCl}, 0.5 \%$ (v/v) Nonidet P-40], incubated on ice for $15 \mathrm{~min}$ and centrifuged at $300 \mathrm{x} \mathrm{g}$ for $3 \mathrm{~min}$ at $4^{\circ} \mathrm{C}$. The nuclei were resuspended in FA lysis buffer (50 mM HEPES, pH 7.5, $150 \mathrm{mM} \mathrm{NaCl}$, $1 \%$ Triton $\mathrm{X}-100,0.1 \%$ sodium deoxycholate, $0.1 \%$ SDS, $1 \mathrm{X}$ protease inhibitor) and incubated at room temperature for $10 \mathrm{~min}$. Prior to sonication, $50 \mathrm{mg}$ of glass beads (G1277, Sigma-Aldrich; Merck KGaA) was added to each sample. The samples were sonicated on ice with the Sonic Dismembrator Model 100 (Thermo Fisher Scientific, Inc.) with a microtip probe set to a power output of 4-6 W for 10 cycles of $10 \mathrm{sec}$ pulse $/ 50 \mathrm{sec}$ rest and then microcentrifuged at $300 \mathrm{x}$ g for $3 \mathrm{~min}$ at $4^{\circ} \mathrm{C}$. Dynabeads Protein G (Thermo Fisher Scientific, Inc.) were blocked with bovine serum albumin/salmon sperm DNA and incubated for $10 \mathrm{~min}$ at room temperature with $5 \mu \mathrm{g}$ of appropriate antibodies or negative control normal mouse IgG (cat. no. sc-2025; Santa Cruz Biotechnology, Inc.), DNMT1 (cat. no. ab13537; Abcam), DNMT3a (sc-20703; Santa Cruz Biotechnology, Inc.) and DNMT3b (cat. no. sc-20704, Santa Cruz Biotechnology). Sonicated chromatin was added to the Dynabead-antibody complexes and rotated at $4^{\circ} \mathrm{C}$ for $\sim 16 \mathrm{~h}$. Whole cell lysate were prepared as positive control. The beads were washed and cross-linked by addition of $\mathrm{NaCl}$ to a final concentration of $250 \mathrm{mM}$, followed by boiling for $15 \mathrm{~min}$ and treatment with proteinase $\mathrm{K}$. HBV was detected using PCR with specific primers as described previously (14). Western blotting was performed as follows: Total protein was extracted from HepG2cells using RIPA buffer (50 mM Tris- $\mathrm{HCl} \mathrm{pH} 7.4$, $150 \mathrm{mM} \mathrm{NaCl}, 1 \mathrm{mM}$ EDTA, 1\% Triton X-100, 0.5\% Sodium deoxycholate, $0.1 \%$ SDS). The protein was quantified by bicinchoninic acid assay. Protein $(100 \mu \mathrm{g})$ was separated per lane via $8 \%$ SDS-PAGE and transferred onto a polyvinylidene difluoride membrane (Roche Diagnostics $\mathrm{GmbH}$ ). The membranes were blocked with $2.5 \%$ skimmed milk in PBS with $0.1 \%$ Tween 20 for $1 \mathrm{~h}$ at room temperature. The membranes were incubated with the following primary antibodies overnight at $4^{\circ} \mathrm{C}$ : Mouse monoclonal anti- $\beta$-actin (cat. no. sc69879; dilution 1:2,000; Santa Cruz Biotechnology, Inc.), mouse monoclonal anti-DNMT 3a (cat. no. ab13888; dilution 1:1,000; Abcam), mouse monoclonal anti-DNMT 3b (cat. no. ab13604; dilution 1:1,000; Abcam). The membranes were subsequently incubated with horseradish peroxidase-conjugated goat anti-mouse IgG secondary antibody (cat. no. sc2005; dilution 1:2,000; Santa Cruz Biotechnology, Inc.) for $1 \mathrm{~h}$ at room temperature. Signals were detected by exposure of the blot to X-ray film using SuperSignal West Pico Chemiluminescent Substrate (Thermo Fisher Scientific, Inc.). ImageJ software (version 1.46; the National Institutes of Health) was used for measuring the intensity of bands in film image. The promoter 


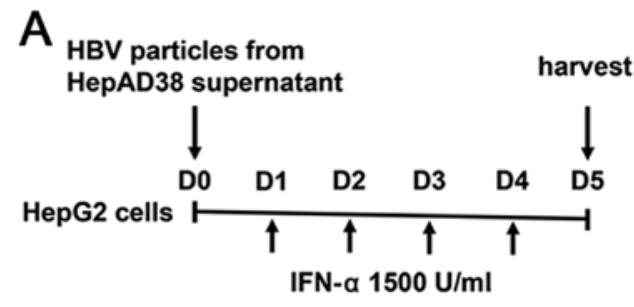

B

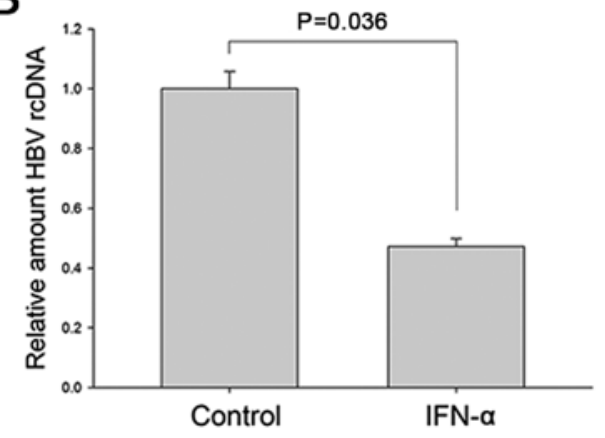

C

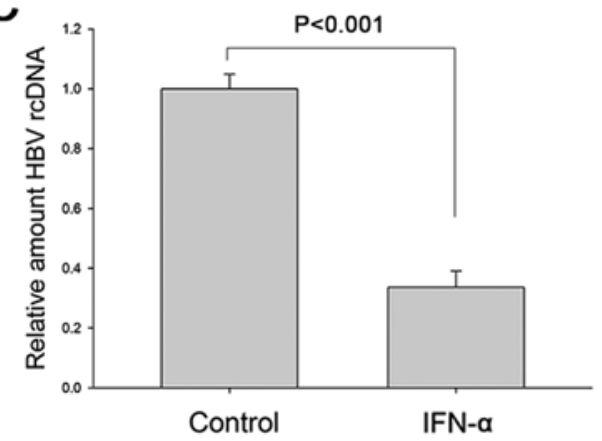

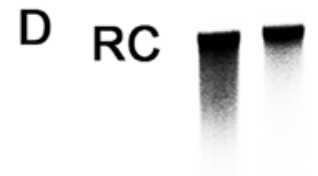

\section{SS}

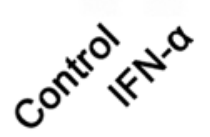

$\mathrm{E}$

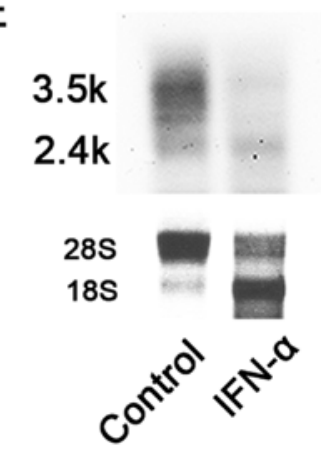

Figure 1. IFN- $\alpha$ suppresses HBV transcripts in HepG2 cells. (A) HBV virion particles were collected from the supernatant of HepAD38 cells and added to HepG2 cells at a titer of 50 MOI. On the following day, IFN- $\alpha$ was added at a final concentration of 1,500 U/ml for four days before harvest. (B) and (C) PCR showed suppression of HBV DNA by IFN- $\alpha$ treatment in cytoplasm and culture supernatant, respectively. (D) Southern blot assay revealed suppression of HBV rcDNA following IFN- $\alpha$ treatment. (E) Northern blot assay revealed suppression of HBV pregenomic/precore RNA (3.5 kb) by IFN- $\alpha$ treatment. Error bars represent standard error of the mean $(n=3)$. HBV, hepatitis B virus; MOI, multiplicity of infection; RC/rcDNA, relaxed circular DNA; SS, single-strand HBV DNA replicative intermediates.

of DNMT3b was cloned into the pGL3-basic vector and used for the luciferase assay with normalization to Renilla luciferase in the pRL-TK plasmid according to the instructions of the manufacturer. Briefly, $24 \mathrm{~h}$ after transfection of pGL3-DNMT3b promoter $(1 \mu \mathrm{g})$ and pRL-TK (100 $\mathrm{ng})$ into HepG2 cells (5x10 cells) using Lipofectamine $2000^{\circledR}$ (Thermo Fisher Scientific), luciferase activity was quantified by using a Dual-Luciferase Reporter Assay kit (Promega Corporation).

Statistical analysis. Continuous data were analyzed by using unpaired Student's t test except for comparison of real-time PCR data which were made by pairwise fixed reallocation randomization test using REST software (REST 2009 version 2.0.13; Qiagen GmbH; https://www.gene-quantification.de/rest-2009.html) (46). At least three experiments were repeated and the results were presented as the mean \pm standard deviation. Comparison of bisulfite sequencing data was made by Fisher's exact test. $\mathrm{P}<0.05$ was considered to indicate a statistically significant difference.

\section{Results}

IFN- $\alpha$ suppresses $H B V$ replication in HepG 2 cells. In the cell-based HBV replication model of the present study HepG2 cells were infected with concentrated HBV virion particles, rather than $\mathrm{HBV}$-expressing plasmids, in order to exclude the possibility of carrier plasmid DNA serving as a source of methylation and of engineered promoters being responsive to IFN (47). IFN- $\alpha$ was replenished daily for four days to ensure sufficient time for methylation as that in our previous study (Fig. 1A) (42). The model showed that IFN- $\alpha$ treatment suppressed the intracellular HBV DNA (Fig. 1B and D) and HBV DNA secretion to culture supernatant (Fig. 1C). IFN- $\alpha$ also reduced HBV RNA, suggesting the possibility of transcriptional suppression (Fig. 1E).

IFN- $\alpha$ does not affect methylation profiles of $H B V$ cccDNA in HepG2 cells. Since methylation of HBV cccDNA has been identified as a mechanism of regulating HBV replication both 
A
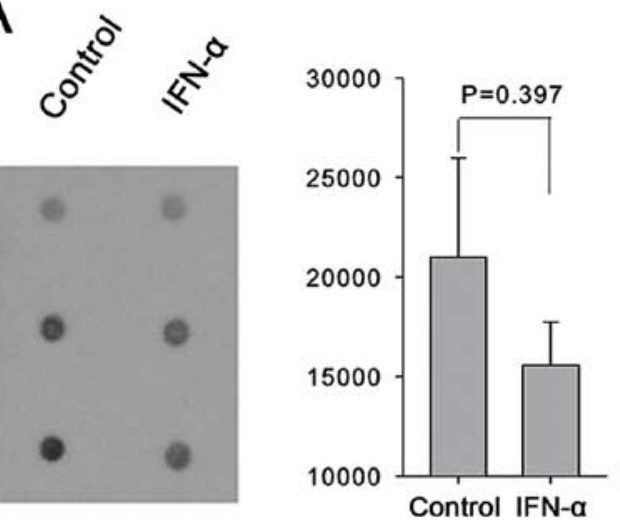

B
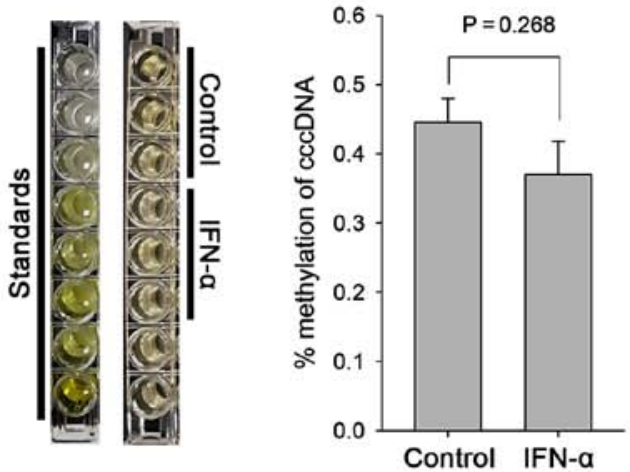

C

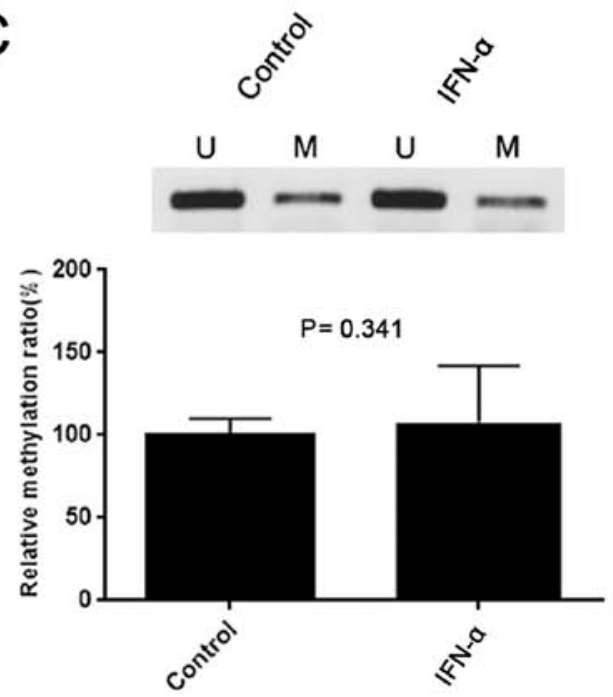

D
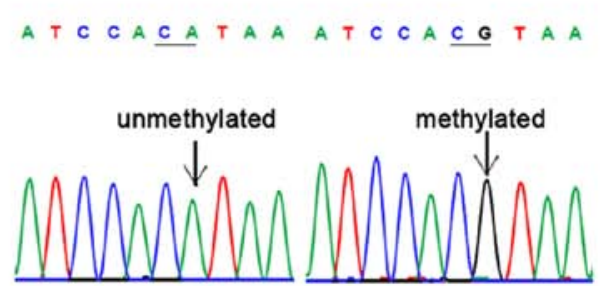

E

Control $(n=52)$

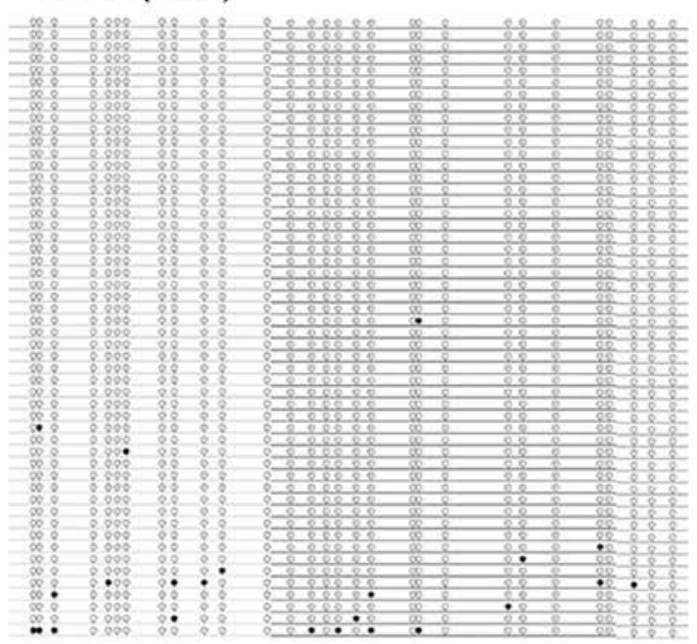

IFN- $\alpha(n=70)$

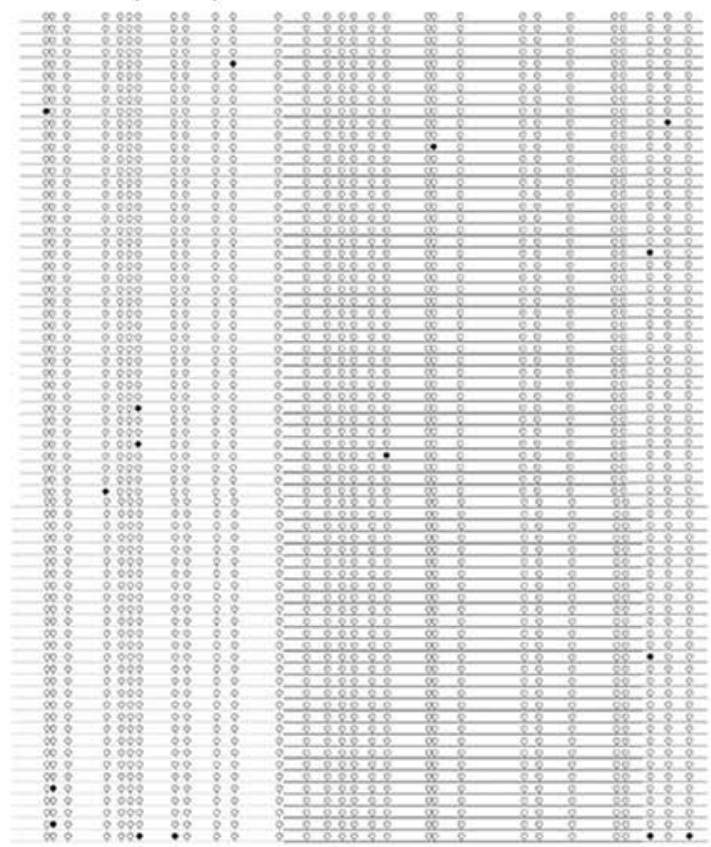

Figure 2. Methylation profile of HBV cccDNA is not influenced by IFN- $\alpha$ in HepG2 cells. (A) 5-mC dot blot analysis showed similar degrees of global methylation of HBV cccDNA between control and IFN- $\alpha$ treated groups (triplicates, left panel; densitometric measurement, right panel). (B) Global DNA methylation ELISA assay also found no difference between the two groups (triplicates, left panel, ELISA reading values, right panel). (C) Methylation-specific PCR revealed no difference in CpG island II methylation between the control and IFN- $\alpha$ treated groups. Bars in lower panel indicate ratio of densitometric measurements of methylated-to-unmethylated bands. (D) Bisulfite sequencing converted CG to TG in HBV cccDNA without CpG methylation (CA in a complementary sequence, left panel), whereas methylated $\mathrm{CpG}$ sequences were not modified by bisulfite treatment (right panel). (E) Bisulfite sequencing analysis showed that the frequencies of $\mathrm{CpG}$ island II methylation were similar between the control and IFN- $\alpha$ treated groups (11/52 vs. 13/70; P=0.723). Error bars represent standard error of the mean $(n=3)$. HBV, hepatitis B virus; cccDNA, covalently closed circular DNA.

in vitro and in vivo $(17-20,48)$, the present study sought to determine whether the anti-HBV effect of IFN- $\alpha$ was also mediated through cccDNA methylation. First, global methylation level was assessed using 5-mC dot blot assay, which showed that IFN- $\alpha$ did not affect the overall level of HBV cccDNA methylation (Fig. 2A). Global DNA methylation ELISA assay 
A

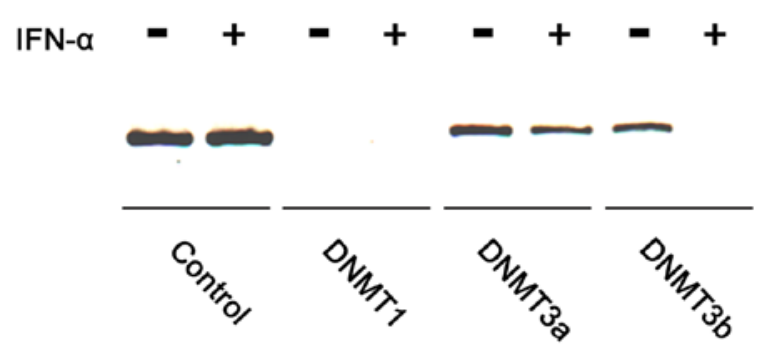

B
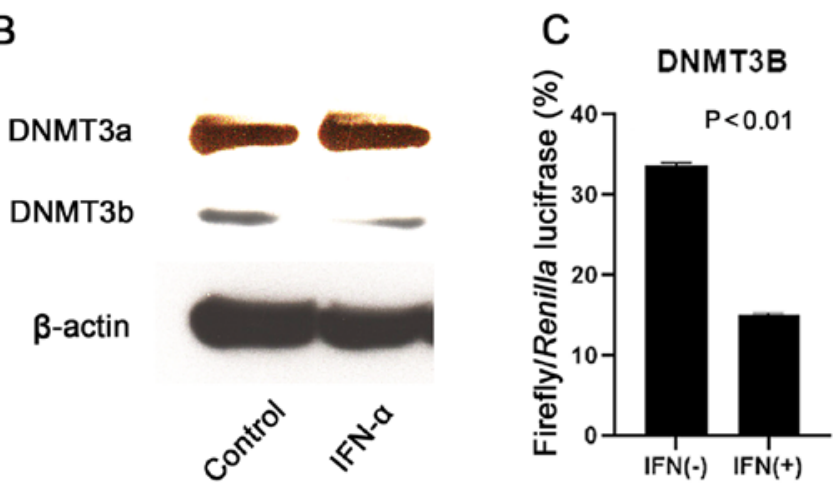

Figure 3. IFN- $\alpha$ suppresses the association between DNMT3b and HBV cccDNA. (A) Chromatin immunoprecipitation assay showed that DNMT3a and DNMT3b bound to HBV cccDNA in HepG2 cells. Treatment with IFN- $\alpha$ did not affect DNMT3a binding, but suppressed DNMT3b binding to cccDNA. (B) Western blot analysis revealed that IFN- $\alpha$ did not affect the expression of DNMT3a, but downregulated DNMT3b in HepG2 cells. (C) Luciferase assay showed decreased promoter activity of DNMT3b in response to IFN- $\alpha$ treatment in HepG2 cells $(\mathrm{P}<0.01)$. The $y$-axis indicates the relative activity (\%) of firefly luciferase driven by the DNMT3b promoter normalized to Renilla luciferase driven by the HSV TK promoter. Error bars represent standard error of the mean $(n=5)$. DNMT, DNA methyltransferase; HBV, hepatitis B virus; cccDNA, covalently closed circular DNA.

also confirmed no difference of the degree of methylation between control and IFN- $\alpha$ treated group (Fig. 2B). Next, methylation-specific PCR showed that IFN- $\alpha$ did not alter the level of methylation in $\mathrm{CpG}$ island II, which regulates the $\mathrm{X}$ promoter of HBV cccDNA (Fig. 2C) (49). Bisulfite sequencing also confirmed a similar degree of methylation in $\mathrm{CpG}$ island II of HBV cccDNA regardless of interferon treatment $(11 / 52$ for control and 13/70 for IFN- $\alpha$; $\mathrm{P}=0.723$; Fig. 2D and $\mathrm{E}$ ).

IFN- $\alpha$ suppressess DNMT3b binding to HBV cccDNA. Finally, the present study determined the effect of IFN- $\alpha$ on the association of DNMTs with HBV cccDNA. ChIP assay confirmed that DNMT1 did not bind to HBV cccDNA, but DNMT3a and DNMT3b were associated with cccDNA (Fig. 3A). Notably, IFN- $\alpha$ suppressed the binding of DNMT3b to cccDNA. Western blotting demonstrated decreased DNMT3b protein expression induced by IFN- $\alpha$ (Fig. 3B). The luciferase assay indicated that IFN- $\alpha$ suppressed DNMT3b promoter activity in HepG2 cells (Fig. 3C).

\section{Discussion}

Methylation of cccDNA has recently received considerable attention as a mechanism of transcriptional regulation in human HBV infection (10). The present authors and other researchers have shown that methylation of cccDNA suppresses the transcriptional activity of cccDNA in cell-based models $(17,18,20)$. In addition, cccDNA methylation is frequently observed in the immunologically controlled stages of chronic HBV infection with low viremia $(20,22)$. However, the underlying mechanisms of de novo methylation of cccDNA are largely unknown.

The anti-HBV effect of IFN- $\alpha$ simulates the host immune response against chronic $\mathrm{HBV}$ infection; i.e., sustained inhibition of viral gene transcription (5), loss of HBeAg and decrease in HBsAg titers (50). Epigenetic regulation may serve as a shared mechanism between sustained anti-HBV response to IFN- $\alpha$ and the low viremia phase of chronic HBV infection (20,30). While IFN-induced PTMs of histone proteins have been well established $(14,15,29)$, only one previous report that assessed the effect of IFN- $\alpha$ on cccDNA methylation was found, which found a total lack of methylation in both control and IFN-treated cccDNA (30). In that study, however, $\mathrm{CpG}$ island I was sequenced, which is barely methylated in the advanced stage of chronic HBV infection and is not related to transcriptional control of cccDNA in previous studies $(22,51)$.

The present study hypothesized that cccDNA methylation may also contribute to the IFN-mediated transcriptional suppression of HBV. To test this hypothesis, our previous cell-based model was used to generate a condition for cccDNA methylation, with some modifications (39). First, direct infection with wild-type HBV virions $(52,53)$ was used instead of plasmid-mediated in vitro HBV models (30), because CpG-containing plasmids may trigger inflammatory cytokine responses and become inadvertently methylated (54). The model of the present study, although it has low efficacy for HBV infection due to the lack of sodium taurocholate cotransporting polypeptide (37), has an advantage over transfection of greater-than-genome HBV plasmid or HBV-producing cell lines in which newly generated HBV cccDNA cannot be differentiated from the transfected plasmids or pre-formed cccDNA. Second, conditionally HBV-producing cell lines are avoided because the tetracycline-responsive promoter contains functional interferon-inducible response elements (47). The baseline methylation of HBV cccDNA was confirmed without interferon treatment (Fig. 2), indicating the presence of methylation machinery against natural HBV infection, as previously suggested $(20,42)$.

IFN- $\alpha$ suppressed HBV replication in the cell model of the present study. Contrary to the authors' prediction, however, extensive bisulfite sequencing experiments did not detect significant differences in the level of cccDNA methylation between control and IFN- $\alpha$-treated groups. Therefore, the anti-HBV effect of IFN- $\alpha$ is unlikely to be mediated by DNA methylation. Recently, DNA methylation has been proposed as a target of epigenetic therapy for CHB (10). Despite the negative result of the present study it is hypothesized that modulation of cccDNA methylation may still be pursued to enhance the therapeutic efficacy of IFN.

Mammalian de novo DNA methylation is mediated by DNMT3A and DNMT3B (55). DNMT3a is suggested to induce de novo HBV cccDNA methylation (19). The ChIP data confirmed the association of both DNMT3a and DNMT3b with HBV cccDNA (Fig. 3A). The data also suggested that innate interferon response is not the main mechanism of $\mathrm{HBV}$ methylation and that ISGs are not sufficient for methylation 
of cccDNA. which is in contrast to the fact that downstream signaling of interferon modifies cccDNA-bound histones (56). Thus, the underlying mechanisms of de novo cccDNA methylation by DNMTs still remain largely unknown. The data of the present study does not necessarily exclude the potential participation of ISGs as a mechanism underlying DNA methylation in mammalian cells. Whether additional inflammatory cytokines such as TNF $\alpha$ and IFN $\gamma$ or small RNAs may cooperate with IFN signaling to induce cccDNA methylation needs to be clarified by further studies.

There have been reports demonstrating that HBV induces de novo methylation of ISGs, leading to suppression of anti-HBV innate signaling of IFN $(57,58)$. It is not known whether innate IFN response counter-attacks HBV epigenetically, but it is plausible considering the fact that IFN- $\alpha$ may induce reversible DNA demethylation of ISGs (59). The finding of the present study that IFN- $\alpha$ suppressed DNMT3b expression and DNA binding may also be in line with the hypothesis, but further studies are warranted.

Since HepG2 cells were maintained in the presence of fetal bovine serum (FBS) throughout the experiments, the possibility that various cytokines in FBS may affect the results cannot be excluded. Serum-free culture condition is difficult to maintain in our cell model because our previous data showed that $\geq 5$ days were needed before methylation of HBV cccDNA was induced (39). Other related studies also used similar study design with serum in culture media $(16,30)$ and it is hypothesized that possible effect of cytokines may have been adjusted by comparison with the control with same culture condition (except for IFN). However, potential interactions between IFN and other cytokines need to be explored in future studies.

The present study has some limitations. First, it did not sort HepG2 cells according to intracellular HBV replication after treatment with HBV particles. However, it was presumed that the efficacy of HBV infection should be similar between control and IFN-treated cells. In addition, the degree of methylation was assessed by normalization to total cccDNA, so that the results are independent of the efficacy of HBV infection. Second, methylation of cccDNA was evaluated in liver cancer cells and the possibility that normal hepatocytes may show different pattern of methylation cannot be excluded.

In conclusion, methylation of HBV cccDNA was not induced by IFN- $\alpha$, which suggested that it is not responsible for the antiviral effect of IFN- $\alpha$ against HBV in HepG2 cells and that alternative mechanisms need to be sought to enhance cccDNA methylation as a novel therapy against HBV.

\section{Acknowledgements}

Not applicable.

\section{Funding}

This study was supported by the Seoul National University Bundang Hospital (grant no.03-2010-001) to Dr Jin-Wook Kim.

\section{Availability of data and materials}

The datasets used and/or analyzed during the current study are available from the corresponding author on reasonable request.

\section{Authors' contributions}

IYM and JWK designed the study; IYM performed the experiments; IYM and JWK analyzed the data and contributed to the final manuscript. Both authors read and approved the final manuscript and confirm the authenticity of all the raw data.

\section{Ethics approval and consent to participate}

Not applicable.

\section{Patient consent for publication}

Not applicable.

\section{Competing interests}

The authors declare that they have no competing interests.

\section{References}

1. Yuen MF, Chen DS, Dusheiko GM, Janssen HLA, Lau DTY, Locarnini SA, Peters MG and Lai CL: Hepatitis B virus infection. Nat Rev Dis Primers 4: 18035, 2018.

2. Seeger C and Mason WS: Hepatitis B virus biology. Microbiol Mol Biol Rev 64: 51-68, 2000.

3. Nassal M: HBV cccDNA: Viral persistence reservoir and key obstacle for a cure of chronic hepatitis B. Gut 64: 1972-1984, 2015.

4. Trepo C, Chan HL and Lok A: Hepatitis B virus infection. Lancet 384: 2053-2063, 2014.

5. Volz T, Lutgehetmann M, Wachtler P, Jacob A, Quaas A, Murray JM, Dandri M and Petersen J: Impaired intrahepatic hepatitis B virus productivity contributes to low viremia in most HBeAg-negative patients. Gastroenterology 133: 843-852, 2007.

6. Suslov A, Meier MA, Ketterer S, Wang X, Wieland S and Heim MH: Transition to HBeAg-negative chronic hepatitis B virus infection is associated with reduced cccDNA transcriptional activity. J Hepatol 74: 794-800, 2021.

7. Moolla N, Kew M and Arbuthnot P: Regulatory elements of hepatitis B virus transcription. J Viral Hepat 9: 323-331, 2002.

8. Xia Y and Guo H: Hepatitis B virus cccDNA: Formation, regulation and therapeutic potential. Antiviral Res 180: 104824, 2020.

9. Oropeza CE, Tarnow G, Sridhar A, Taha TY, Shalaby RE and McLachlan A: The regulation of $\mathrm{HBV}$ transcription and replication. Adv Exp Med Biol 1179: 39-69, 2020.

10. Hong X, Kim ES and Guo H: Epigenetic regulation of hepatitis B virus covalently closed circular DNA: Implications for epigenetic therapy against chronic hepatitis B. Hepatology 66: 2066-2077, 2017.

11. Dandri M: Epigenetic modulation in chronic hepatitis B virus infection. Semin Immunopathol 42: 173-185, 2020.

12. Bock CT, Schranz P, Schroder CH and Zentgraf H: Hepatitis B virus genome is organized into nucleosomes in the nucleus of the infected cell. Virus Genes 8: 215-229, 1994.

13. Bock CT, Schwinn S, Locarnini S, Fyfe J, Manns MP, Trautwein C and Zentgraf H: Structural organization of the hepatitis B virus minichromosome. J Mol Biol 307: 183-196, 2001.

14. Pollicino T, Belloni L, Raffa G, Pediconi N, Squadrito G, Raimondo $G$ and Levrero $M$ : Hepatitis $B$ virus replication is regulated by the acetylation status of hepatitis $B$ virus cccDNA-bound $\mathrm{H} 3$ and $\mathrm{H} 4$ histones. Gastroenterology 130: $823-837,2006$

15. Tropberger P, Mercier A, Robinson M, Zhong W, Ganem DE and Holdorf M: Mapping of histone modifications in episomal HBV cccDNA uncovers an unusual chromatin organization amenable to epigenetic manipulation. Proc Natl Acad Sci USA 112: E5715-E5724, 2015.

16. Yuan Y, Yuan H, Yang G, Yun H, Zhao M, Liu Z, Zhao L, Geng Y, Liu L, Wang J, et al: IFN- $\alpha$ confers epigenetic regulation of HBV cccDNA minichromosome by modulating GCN5-mediated succinylation of histone $\mathrm{H} 3 \mathrm{~K} 79$ to clear HBV cccDNA. Clin Epigenetics 12: 135, 2020. 
17. Guo Y, Li Y, Mu S, Zhang J and Yan Z: Evidence that methylation of hepatitis $B$ virus covalently closed circular DNA in liver tissues of patients with chronic hepatitis B modulates HBV replication. J Med Virol 81: 1177-1183, 2009.

18. Vivekanandan P, Thomas D and Torbenson M: Methylation regulates hepatitis B viral protein expression. J Infect Dis 199: 1286-1291, 2009.

19. Vivekanandan P, Daniel HD, Kannangai R, Martinez-Murillo F and Torbenson M: Hepatitis B virus replication induces methylation of both host and viral DNA. J Virol 84: 4321-4329, 2010.

20. Kim JW, Lee SH, Park YS, Hwang JH, Jeong SH, Kim N and Lee DH: Replicative activity of hepatitis B virus is negatively associated with methylation of covalently closed circular DNA in advanced hepatitis B virus infection. Intervirology 54: 316-325, 2011.

21. Zhang Y, Li C, Zhang Y, Zhu H, Kang Y, Liu H, Wang J, Qin Y, Mao R, Xie Y, et al: Comparative analysis of $\mathrm{CpG}$ islands among HBV genotypes. PLoS One 8: e56711, 2013.

22. Zhang Y, Mao R, Yan R, Cai D, Zhang Y, Zhu H, Kang Y, Liu H, Wang J, Qin Y, et al: Transcription of hepatitis B virus covalently closed circular DNA is regulated by $\mathrm{CpG}$ methylation during chronic infection. PLoS One 9: e110442, 2014.

23. Zhang ZM, Lu R, Wang P, Yu Y, Chen D, Gao L, Liu S, Ji D, Rothbart SB, Wang Y, et al: Structural basis for DNMT3A-mediated de novo DNA methylation. Nature 554: 387-391, 2018

24. Konerman MA and Lok AS: Interferon treatment for hepatitis B. Clin Liver Dis 20: 645-665, 2016.

25. Wieland SF, Guidotti LG and Chisari FV: Intrahepatic induction of alpha/beta interferon eliminates viral RNA-containing capsids in hepatitis B virus transgenic mice. J Virol 74: 4165-4173, 2000

26. Xiong W, Wang X, Liu X, Xiang L, Zheng L and Yuan Z: Interferon-inducible MyD88 protein inhibits hepatitis B virus replication. Virology 319: 306-314, 2004.

27. Lucifora J, Xia Y, Reisinger F, Zhang K, Stadler D, Cheng X, Sprinzl MF, Koppensteiner H, Makowska Z, Volz T, et al: Specific and nonhepatotoxic degradation of nuclear hepatitis B virus cccDNA. Science 343: 1221-1228, 2014.

28. Cheng J, Zhao Q, Zhou Y, Tang L, Sheraz M, Chang J and Guo JT: Interferon alpha induces multiple cellular proteins that coordinately suppress hepadnaviral covalently closed circular DNA transcription. J Virol 94: e00442-20, 2020.

29. Belloni L, Allweiss L, Guerrieri F, Pediconi N, Volz T, Pollicino T, Petersen J, Raimondo G, Dandri M and Levrero M: IFN- $\alpha$ inhibits HBV transcription and replication in cell culture and in humanized mice by targeting the epigenetic regulation of the nuclear cccDNA minichromosome. J Clin Invest 122: 529-537, 2012.

30. Liu F, Campagna M, Qi Y, Zhao X, Guo F, Xu C, Li S, Li W, Block TM, Chang J and Guo JT: Alpha-interferon suppresses hepadnavirus transcription by altering epigenetic modification of cccDNA minichromosomes. PLoS Pathog 9: e1003613, 2013.

31. Allweiss L, Volz T, Lutgehetmann M, Giersch K, Bornscheuer T, Lohse AW, Petersen J, Ma H, Klumpp K, Fletcher SP and Dandri M: Immune cell responses are not required to induce substantial hepatitis B virus antigen decline during pegylated interferon-alpha administration. J Hepatol 60: 500-507, 2014

32. Ladner SK, Otto MJ, Barker CS, Zaifert K, Wang GH, Guo JT, Seeger $\mathrm{C}$ and King RW: Inducible expression of human hepatitis $B$ virus (HBV) in stably transfected hepatoblastoma cells: A novel system for screening potential inhibitors of HBV replication. Antimicrob Agents Chemother 41: 1715-1720, 1997.

33. Qiao L, Sui J and Luo G: Robust human and murine hepatocyte culture models of hepatitis B virus infection and replication. J Virol 92: e01255-18, 2018.

34. Paran N, Geiger B and Shaul Y: HBV infection of cell culture: Evidence for multivalent and cooperative attachment. EMBO J 20: 4443-4453, 2001

35. Sohn JA, Litwin S and Seeger C: Mechanism for CCC DNA synthesis in hepadnaviruses. PLoS One 4: e8093, 2009.

36. Garner I: Isolation of high-molecular-weight DNA from animal cells. In: The nucleic acid protocols handbook. Rapley R (ed). Humana Press, Totowa, NJ, pp 3-7, 2000.

37. Yan H, Zhong G, Xu G, He W, Jing Z, Gao Z, Huang Y, Qi Y, Peng $\mathrm{B}$, Wang $\mathrm{H}$, et al: Sodium taurocholate cotransporting polypeptide is a functional receptor for human hepatitis B and D virus. Elife 1: e00049, 2012.

38. Bowden S, Jackson K, Littlejohn $M$ and Locarnini $S$ Quantification of HBV covalently closed circular DNA from liver tissue by real-time PCR. Methods Mol Med 95: 41-50, 2004
39. Moon IY, Choi JH, Chung JW, Jang ES, Jeong SH and Kim JW: MicroRNA20 induces methylation of hepatitis B virus covalently closed circular DNA in human hepatoma cells. Mol Med Rep 20: 2285-2293, 2019.

40. Min BY, Kim NY, Jang ES, Shin CM, Lee SH, Park YS Hwang JH, Jeong SH, Kim N, Lee DH and Kim JW: Ethanol potentiates hepatitis $\mathrm{B}$ virus replication through oxidative stress-dependent and -independent transcriptional activation. Biochem Biophys Res Commun 431: 92-97, 2013.

41. Jia Z, Liang Y, Ma B, Xu X, Xiong J, Duan L and Wang D: A 5 -mC dot blot assay quantifying the DNA methylation level of chondrocyte dedifferentiation in vitro. J Vis Exp 55565, 2017.

42. Park HK, Min BY, Kim NY, Jang ES, Shin CM, Park YS, Hwang JH, Jeong SH, Kim N, Lee DH and Kim JW: Short hairpin RNA induces methylation of hepatitis B virus covalently closed circular DNA in human hepatoma cells. Biochem Biophys Res Commun 436: 152-155, 2013.

43. Vivekanandan P, Thomas D and Torbenson M: Hepatitis B viral DNA is methylated in liver tissues. J Viral Hepat 15: 103-107, 2008.

44. Bock C, Reither S, Mikeska T, Paulsen M, Walter J and Lengauer T: BiQ Analyzer: Visualization and quality control for DNA methylation data from bisulfite sequencing. Bioinformatics 21: 4067-4068, 2005.

45. Aparicio O, Geisberg JV, Sekinger E, Yang A, Moqtaderi Z and Struhl K: Chromatin immunoprecipitation for determining the association of proteins with specific genomic sequences in vivo. Curr Protoc Mol Biol 21 (Suppl 69): 21.3.1-21.3.33, 2005.

46. Pfaffl MW, Horgan GW and Dempfle L: Relative expression software tool (REST) for group-wise comparison and statistical analysis of relative expression results in real-time PCR. Nucleic Acids Res 30: e36, 2002.

47. Rang $\mathrm{A}$ and Will $\mathrm{H}$ : The tetracycline-responsive promoter contains functional interferon-inducible response elements. Nucleic Acids Res 28: 1120-1125, 2000.

48. Zhang X, Hou J and Lu M: Regulation of hepatitis B virus replication by epigenetic mechanisms and microRNAs. Front Genet 4: 202, 2013.

49. Zhong C, Lu H, Han T, Tan X, Li P, Huang J, Xie Q, Hou Z, Qu T, Jiang Y, et al: $\mathrm{CpG}$ methylation participates in regulation of hepatitis $B$ virus gene expression in host sperm and sperm-derived embryos. Epigenomics 9: 123-125, 2017.

50. Tan G, Song H, Xu F and Cheng G: When Hepatitis B virus meets interferons. Front Microbiol 9: 1611, 2018.

51. Jain S, Chang TT, Chen S, Boldbaatar B, Clemens A, Lin SY, Yan R, Hu CT, Guo H, Block TM, et al: Comprehensive DNA methylation analysis of hepatitis B virus genome in infected liver tissues. Sci Rep 5: 10478, 2015.

52. Bchini R, Capel F, Dauguet C, Dubanchet S and Petit MA: In vitro infection of human hepatoma (HepG2) cells with hepatitis B virus. J Virol 64: 3025-3032, 1990.

53. Mabit H, Dubanchet $S$, Capel F, Dauguet $C$ and Petit MA: In vitro infection of human hepatoma cells (HepG2) with hepatitis B virus (HBV): Spontaneous selection of a stable HBV surface antigen-producing HepG2 cell line containing integrated HBV DNA sequences. J Gen Virol 75 ( Pt 10): 2681-2689, 1994.

54. Mitsui M, Nishikawa M,Zang L, Ando M, Hattori K, Takahashi Y, Watanabe Y and Takakura Y: Effect of the content of unmethylated $\mathrm{CpG}$ dinucleotides in plasmid DNA on the sustainability of transgene expression. J Gene Med 11: 435-443, 2009.

55. Okano M, Bell DW, Haber DA and Li E: DNA methyltransferases Dnmt3a and Dnmt3b are essential for de novo methylation and mammalian development. Cell 99: 247-257, 1999.

56. Yang Y, Zhao X, Wang Z, Shu W, Li L, Li Y, Guo Z, Gao B and Xiong S: Nuclear sensor interferon-inducible protein 16 inhibits the function of hepatitis B virus covalently closed circular DNA by integrating innate immune activation and epigenetic suppression. Hepatology 71: 1154-1169, 2020.

57. Lim KH, Park ES, Kim DH, Cho KC, Kim KP, Park YK Ahn SH, Park SH, Kim KH, Kim CW, et al: Suppression of interferon-mediated anti-HBV response by single $\mathrm{CpG}$ methylation in the 5'-UTR of TRIM22. Gut 67: 166-178, 2018.

58. Zheng DL, Zhang L, Cheng N, Xu X, Deng Q, Teng XM, Wang KS, Zhang X, Huang J and Han ZG: Epigenetic modification induced by hepatitis $B$ virus $X$ protein via interaction with de novo DNA methyltransferase DNMT3A. J Hepatol 50: 377-387, 2009.

59. Scott R, Siegrist F, Foser S and Certa U: Interferon-alpha induces reversible DNA demethylation of the interferon-induced transmembrane protein-3 core promoter in human melanoma cells. J Interferon Cytokine Res 31: 601-608, 2011.

This work is licensed under a Creative Commons Attribution-NonCommercial-NoDerivatives 4.0 International (CC BY-NC-ND 4.0) License. 